\title{
A National Survey of Centers for Cognitive Disorders and Dementias in Italy
}

\author{
Marco Canevelli ${ }^{\mathrm{a}, \mathrm{b}}$, Alessandra Di Pucchio ${ }^{\mathrm{a}}$, Fabrizio Marzolini ${ }^{\mathrm{a}}$, Flavia Mayer ${ }^{\mathrm{a}}$, Marco Massari ${ }^{\mathrm{c}}$, \\ Emanuela Salvi $^{\mathrm{c}}$, Ilaria Palazzesi ${ }^{\mathrm{a}}$, Eleonora Lacorte ${ }^{\mathrm{a}}$, Ilaria Bacigalupo ${ }^{\mathrm{a}}$, \\ Teresa Di Fiandra ${ }^{\mathrm{d}}$ and Nicola Vanacore ${ }^{\mathrm{a}, *}$ \\ ${ }^{a}$ National Center for Disease Prevention and Health Promotion, Italian National Institute of Health, Rome, Italy \\ ${ }^{\mathrm{b}}$ Department of Human Neuroscience, Sapienza University of Rome, Rome, Italy \\ ${ }^{\mathrm{c}}$ National Center for Drug Research and Evaluation, Italian National Institute of Health, Rome, Italy \\ ${ }^{\mathrm{d}}$ Direction of Prevention, Italian Ministry of Health, Rome, Italy
}

Accepted 2 August 2021

Pre-press 24 August 2021

\begin{abstract}
.
Background: Italy has one of the oldest populations in the World and more than one million dementia cases can be estimated at the national level.

Objective: The objectives of this national survey include: 1) to report the administrative features and the professional competencies of Centers for Cognitive Disorders and Dementias (CCDDs); 2) to document possible discrepancies by geographic macro-area; and 3) to identify the features of CCDDs that are associated with a better quality in the provision of care.

Methods: A survey of Italian CCDDs was conducted between February 2014 and December 2015. A list of CCDDs was obtained through direct interactions with designed delegates from each Italian region. A questionnaire was defined on five sections concerning: 1) location of the $\mathrm{CCDD} ; 2$ ) access to the $\mathrm{CCDD} ; 3$ ) organization of the $\mathrm{CCDD}$; 4) services and treatments provided; and 5) quantitative data on the activities of the CCDD.

Results: Overall, 577 out of the 597 eligible CCDDs returned the completed survey questionnaire (response rate: $96.6 \%$ ): 260 (45.1\%) from Northern Italy, 103 (17.8\%) from Central Italy, and 214 (37.1\%) from Southern-Islands Italy. More than a third of CCDDs were open only once or twice weekly. A median of 450 (IQR: 200-800) patients regularly attended these services. Most patients (70\%) were affected by dementia or mild cognitive impairment (19\%).

Conclusion: We have provided a snapshot of the organization and activities of CCDDs in Italy and documented existing inequalities in the provision of care.
\end{abstract}

Keywords: Cognitive disorders, dementia, healthcare services, memory clinics, public health, services, survey

\section{INTRODUCTION}

Dementia is increasingly recognized as a public health priority and as a threat for the sustainability of our health- and social-care systems [1]. Indeed, it represents a major cause of disability, dependency, and healthcare expenditures worldwide $[2,3]$.

\footnotetext{
${ }^{*}$ Correspondence to: Nicola Vanacore, MD, PhD, National Center for Disease Prevention and Health Promotion, Italian National Institute of Health, Via Giano della Bella 34, 00162 Rome, Italy. Tel.: +39 06 49904243; Fax: +39 06 49904243; E-mail: nicola.vanacore@iss.it.
}

However, a relevant gap still exists between the need for prevention, treatment, and care for dementia and the provision of these services [1].

Since their first establishment in the 1980s [4], memory clinics have acquired a pivotal role in the in the management of dementia and cognitive disturbances in most Western countries [5]. These services are important to ensure timely recognition and differential diagnosis of cognitive disorders. They are often responsible for the prescription of anti-dementia drugs and are active in the provision of non-pharmacological interventions and post-diagnostic 
psychosocial support. There is accumulating evidence that the "memory clinics" model of dementia care, founded on the principles of multidisciplinary approach, timely access to assessments and treatments, and continuity of care, is associated with earlier diagnosis and interventions [6, 7], improved quality of life of caregivers [8], better quality of care [9], and cost-effectiveness [9, 10]. Nevertheless, a relevant heterogeneity in the structure, organization, resourcing, and activities of dementia services has been documented in several countries [11-15].

Italy has one of the oldest populations in the World. More than one million dementia cases can be estimated at the national level (Supplementary Table 1) and more than three million Italians are directly or indirectly involved in the assistance of affected patients [16]. The healthcare and social care costs of dementia amount to 10-12 billion euros/year [17]. The Italian National Dementia Plan was formulated in October 2014 by the Italian Ministry of Health in collaboration with the health and social sectors of all regions, the Italian National Institute of Health, and the three major national associations of patients and caregivers [16, 18]. In the document, the central role of memory clinics in the integrated network of services for dementia was reaffirmed. Moreover, these facilities, originally known as Alzheimer's Evaluation Units [19, 20], were renamed as Centers for Cognitive Disorders and Dementias (CCDDs). CCDDs are currently dedicated to the diagnosis, treatment, and management of patients with dementia and other cognitive disturbances. In Italy, the prescription of anti-dementia drugs (i.e., cholinesterase inhibitors, memantine, and antipsychotics) is entirely entrusted to CCDDs as required by the Italian Medicines Agency. Thus, almost all persons with a potential diagnosis of cognitive decline or dementia are referred, by their general practitioner or other specialists, to these centers. Most CCDDs are public services while only few are private facilities. Their activities are completely covered by the National Health System. CCDDs do not receive dedicated funding for the diagnosis and management of cognitive disorders as they are financially supported by the institutions to which they belong (i.e., universities, research institutes, local health districts, hospitals). There are currently no national standards for the definition and organization of CCDDs. One of the actions envisaged in the plan was the mapping of existing dementia services and resources at the national and regional level with the participation of local communities (Action 1.2) [16]. This activity was deemed as a fundamental step for the design and implementation of dedicated health- and social-care interventions and policies.

In the present study, we describe and discuss the findings of a nation-wide survey of Italian CCDDs. The following objectives were pursued: 1) to report the administrative features and the professional competencies of CCDDs as well as the activities provided by these services; 2) to document possible discrepancies by geographic macro-area in the characteristics and activities of Italian CCDDs; and 3) to exploratorily identify the features of CCDDs that are associated with a better quality in the provision of care.

\section{MATERIALS AND METHODS}

\section{Surveyed services}

The theoretical framework and methodology of the present study have already been described elsewhere [21]. Briefly, a survey of Italian CCDDs was conducted between February 2014 and December 2015. From January 2016 to December 2016, the collected data was reviewed and updated. A list of all national CCDDs was obtained through direct interactions with designed delegates from each Italian region and autonomous province. Such collaborative approach was motivated by the aim of actively involving local authorities in the mapping and monitoring of dementia services and by the fact that these facilities are heterogeneously distributed across the national territory. All surveyed CCDDs are funded by the National Health System and in charge of prescribing specific drugs for Alzheimer's disease (i.e., donepezil, rivastigmine, galantamine, and memantine) based on the diagnosis and treatment plan [22].

The contact details of each CCDD and their representatives were directly provided by regional delegates or obtained from personal and professional contacts and web resources (e.g., websites of healthcare districts). The list of eligible services was constantly checked and updated during the survey with the collaboration of regional and local contacts. The updated list of eligible dementia facilities was validated and/or officially confirmed by regional representatives or regional health departments.

\section{CCDD questionnaire}

A questionnaire was developed by a group of researchers and experts in the field of dementia 
and epidemiology to collect information on various structure, process, and outcome indicators from the surveyed facilities. Specifically, the questionnaire consisted of five sections concerning: 1) location of the CCDD (e.g., name, phone number, address); 2) access to the CCDD (e.g., opening days and hours, how to access the service); 3) organization of the CCDD (e.g., staff composition, waiting times, data collection); 4) services and treatments provided (e.g., pharmacological and psychosocial interventions, neuropsychological assessment, diagnostic procedures, support to caregivers); and 5) quantitative data on the activities of the CCDD in the previous year (e.g., number of overall patients attending the service, number of monthly and annual referrals, amount of neuropsychological assessments) [21]. The survey questionnaire was self-administered and computer assisted. The data was entered in an open data modality and enabled to be checked and updated. Each service was assigned with a unique access code; once authorized, each center was able to fill in the questionnaire in a web-based data entry system. The questionnaire was addressed to the clinical representative of the CCDDs, who were asked to provide information based on last year. Only one response per service was allowed. Most questions were mandatory, and respondents needed to enter a response to move forward. Some automatic checks were included in the questionnaire to avoid inconsistent answers (e.g., it was not possible to write alphabetic characters in fields where numeric data had to be provided).

The questionnaire was piloted with one CCDD to ensure that respondents fully understood questions and instructions. Then, a link to access the online questionnaire was mailed to the available list of national CCDDs through the Dementia Observatory web-platform together with an introductory cover letter explaining the aims of the survey.

Different strategies were adopted to enhance participation and maximize the response rate. For instance, participants were contacted by initial and follow-up emails and offered telephone support, undeliverable contact and/or incorrect e-mail addresses were repeatedly checked and updated, and respondents were able to request assistance for completing the survey.

Data provided by respondents were collected in the online platform and exported for statistical analysis. Since the survey aimed to collect benchmarking data of service provision, the involvement of CCDD clients and formal Ethics approval was not required.

\section{Statistical analysis}

The response rate of contacted CCDDs was used to describe the success and quality of the survey [23]. It was calculated as the percentage of responses out of the total eligible services.

The Shapiro-Wilk test was used to verify the normal distribution of continuous variables and, if necessary, they were reported as median and interquartile ranges (IQR). Categorical variables were instead reported as percentages. CCDDs were grouped into three geographic macro-areas (i.e., North, Center, and South) according to the Italian National Institute of Statistics categorization of regions. The estimated mean number of dementia cases per CCDD in each Italian region was calculated as the ratio between the number of estimated dementia cases at the regional level (see Supplementary Material) and the number of CCDDs mapped in that area. Dementia cases were estimated by multiplying the number of older (i.e., 65+) adults living in each Italian region in 2019 (source: http://demo.istat.it/), stratified by age and sex, and the age- and sex-specific prevalence rates [24]. The characteristics of CCDDs in the three macro-areas were compared by means of Kruskal-Wallis test for continuous variables and chisquare test for categorical variables (Fisher's exact test if necessary).

Three multivariate Poisson regression models with robust variance estimation were conducted to identify the factors predicting: 1) the number of monthly referrals; 2) the proportion of patients with dementia receiving antipsychotics; and 3) waiting time for the first visit. These three indicators were considered as binary dependent variables of interest using their median value as the cut-point. After assessing for absence of multicollinearity, a forward stepwise procedure was used to derive the multivariate model forcing geographic macro-area to stay in. The obtained associations were expressed as prevalence risk ratios (PRR) and 95\% confidence intervals (CIs).

The level of statistical significance was set at $p<0.05$. All analyses were performed using SPSS version 25 for Mac.

\section{RESULTS}

\section{Number, geographic distribution, and estimated catchment area of Italian CCDDs}

Overall, 577 out of the 597 eligible CCDDs returned the completed survey questionnaire 
A

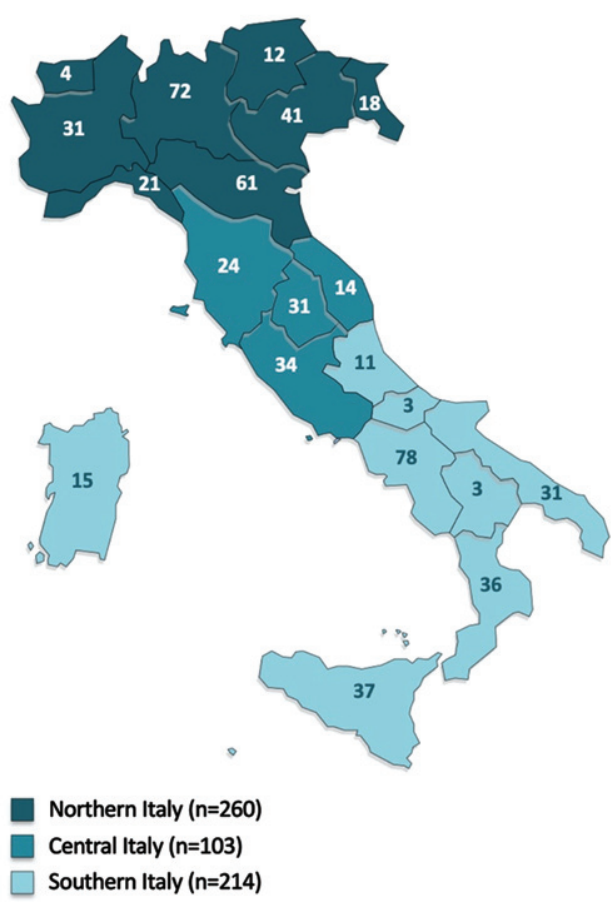

B

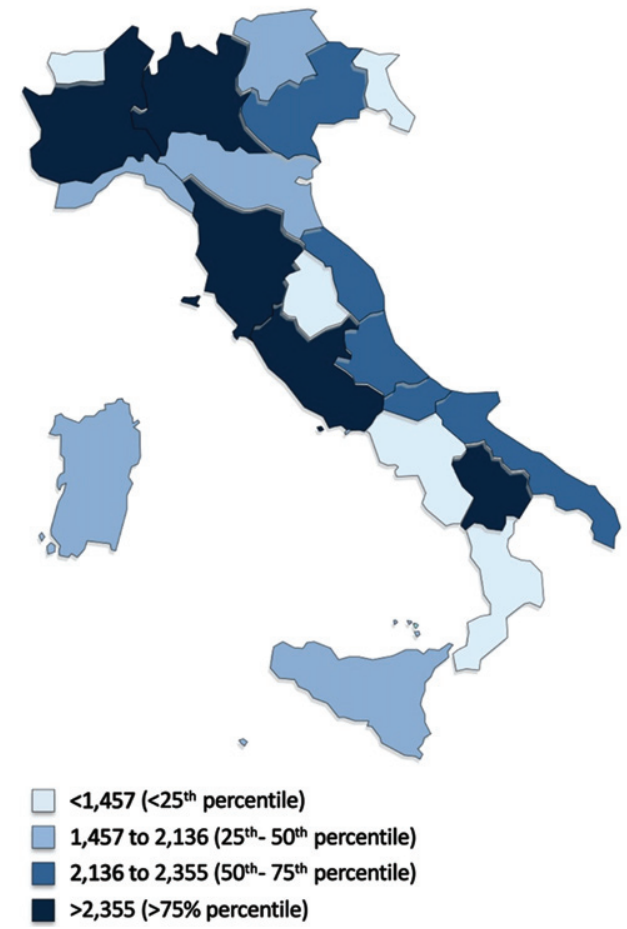

Fig. 1. Geographic distribution of Italian CCDDs and Estimated mean number of dementia cases per CCDD. A) Number of CCDDs in each Italian region. Geographic macro-areas were defined according to the Italian National Institute of Statistics (ISTAT) categorization. B) Estimated mean number of dementia cases per CCDD at the regional level. Dementia cases were estimated by multiplying the number of older (i.e., 65+) adults living in each Italian region in 2019 (source: http://demo.istat.it/) and the age- and sex-specific prevalence rates (21).

(response rate: $96.6 \%): 260$ (45.1\%) from Northern Italy, $103(17.8 \%)$ from Central Italy, and 214 $(37.1 \%)$ from Southern Italy and the islands (Fig. 1A and Table 1).

At the regional level, the estimated mean number of dementia cases per CCDD ranged widely between 589 (Valle D'Aosta) and 3,505 (Basilicata) (median: 2,136; IQR: 1,457-2,355) (Fig. 1B, Supplementary Tables 2 and 3).

\section{Characteristics of the surveyed CCDDs at the national level and by geographic macro-area}

The characteristics of the surveyed CCDDs are presented in Table 1. Most of services were hospitalbased $(50.7 \%)$ and were active three days/week or less $(52.2 \%)$. More than a third of CCDDs were open only once or twice weekly (Fig. 2). Waiting times for the first visits/appointments were mostly lower than three months.

A median of 450 (IQR: 200-800) patients regularly attended these services, with a median of 60 (IQR: $32-105)$ monthly referrals. Most patients $(70 \%)$ were affected by dementia or, less frequently, mild cognitive impairment (19\%) or subjective cognitive decline $(5 \%)$.

A total of 1,558 healthcare professionals (698 medical specialists and 860 other professional staff members including psychologists, administrative staff, and rehabilitation specialists) worked at the surveyed centers and $74 \%$ of them (but only $26 \%$ of psychologists) were employed as permanent staff. Eighty percent of CCDDs reported to provide a comprehensive neuropsychological assessment whereas only a minority of services carried out support activities for caregivers and psychosocial interventions.

With regard to instrumental diagnostic procedures (Table 2), most of services resorted to the execution of routine blood tests, electroencephalography, and brain CT scan. Conversely, only few of them had access to CSF AD biomarkers and functional neuroimaging.

Profound differences were observed across northern, central, and southern Italian regions with regard to CCDDs' location, staff profile and composition, operating days/hours, and services provided (Tables 1 and 2). In particular, CCDDs from the South of Italy were less frequently located in hospitals or 
Table 1

Characteristics of Italian CCDDs at the national level and by geographic macro-area. Data are expressed as \% or median (IQR)

\begin{tabular}{|c|c|c|c|c|c|}
\hline & $\begin{array}{l}\text { Overall } \\
(n=577)\end{array}$ & $\begin{array}{c}\text { North } \\
(n=260)\end{array}$ & $\begin{array}{l}\text { Center } \\
(n=103)\end{array}$ & $\begin{array}{c}\text { South } \\
(n=214)\end{array}$ & $p$ \\
\hline Setting (\%) & & & & & $<0.001$ \\
\hline Territorial & 42.2 & 30.0 & 38.8 & 58.8 & \\
\hline Hospital & 50.7 & 62.6 & 48.0 & 37.7 & \\
\hline University & 7.1 & 7.4 & 13.2 & 3.5 & \\
\hline Opening days/week (\%) & & & & & 0.04 \\
\hline$\leq 3$ & 52.2 & 48.8 & 46.3 & 59.3 & \\
\hline$>3$ & 47.8 & 51.2 & 53.7 & 40.7 & \\
\hline Opening hours/week $(n)$ & $11.8(6.0-24.0)$ & $12.3(6.0-25.5)$ & $14.0(6.0-24.0)$ & $10.0(5.0-21.0)$ & 0.12 \\
\hline Waiting time for the first visit (\%) & & & & & 0.001 \\
\hline$\leq 3$ months & 76.5 & 69.6 & 77.8 & 85.0 & \\
\hline$>3$ months & 23.5 & 30.4 & 22.2 & 15.0 & \\
\hline Overall patients attending the CCDD $(n)$ & $450(200-800)$ & $500(250-900)$ & $600(400-1,000)$ & $250(121-600)$ & $<0.001$ \\
\hline Referrals/month $(n)$ & $60(32-105)$ & $70(40-120)$ & $80(40-115)$ & $40(25-88)$ & $<0.001$ \\
\hline Neuropsychological assessment (\%) & $80.0(40.0-100)$ & $66.0(33.0-100)$ & $70.0(41.3-93.7)$ & $85.0(50.0-100)$ & 0.001 \\
\hline Caregiver support activities (\%) & $10.0(0.0-30.0)$ & $15.0(5.0-30.0)$ & $10.0(0.0-30.0)$ & $10.0(0.0-30.0)$ & 0.06 \\
\hline Psychosocial interventions (\%) & $10.0(0.0-25.0)$ & $10.0(5.0-23.5)$ & $10.0(0.0-30.0)$ & $10.0(0.0-20.0)$ & 0.42 \\
\hline Electronic database $(\%)$ & 69.0 & 82.4 & 78.9 & 47.3 & $<0.001$ \\
\hline Integrated care pathway $(\%)$ & 36.9 & 43.2 & 44.0 & 25.3 & $<0.001$ \\
\hline \multicolumn{6}{|l|}{ Diagnostic categories $(\%)$} \\
\hline Dementia & $70.0(55.0-88.0)$ & $70.0(58.0-80.0)$ & $67.5(56.3-75.0)$ & $70.0(50.0-80.0)$ & 0.70 \\
\hline Mild cognitive impairment & $19.0(10.0-25.0)$ & $15.0(10.0-25.0)$ & $20.0(10.0-25.0)$ & $20.0(10.0-25.0)$ & 0.74 \\
\hline Subjective cognitive decline & $5.0(5.0-10.0)$ & $5.0(4.0-10.0)$ & $10.0(5.0-15.0)$ & $8.0(5.0-11.5)$ & 0.15 \\
\hline Other & $5.0(0.0-10.0)$ & $5.0(0.0-10.0)$ & $4.0(0.0-10.0)$ & $0.0(0.0-10.0)$ & 0.03 \\
\hline \multicolumn{6}{|l|}{ Staff composition (\%) } \\
\hline Neurologists & $18.2(0.0-40.0)$ & $18.2(0.0-38.0)$ & $29.3(0.0-54.2)$ & $12.5(0.0-33.3)$ & $<0.01$ \\
\hline Geriatricians & $14.3(0.0-44.1)$ & $20.0(0.0-43.7)$ & $0.0(0.0-40.0)$ & $12.5(0.0-50.0)$ & 0.25 \\
\hline Psychiatrists & $0.0(0.0-0.0)$ & $0.0(0.0-0.0)$ & $0.0(0.0-0.0)$ & $0.0(0.0-7.1)$ & $<0.001$ \\
\hline Psychologists & $16.7(0.0-33.3)$ & $25.0(12.5-33.3)$ & $11.8(0.0-25.0)$ & $0.0(0.0-21.7)$ & $<0.001$ \\
\hline Administrative staff & $20.0(0.0-36.4)$ & $20.0(0.0-33.3)$ & $13.4(0.0-33.3)$ & $28.6(0.0-46.9)$ & $<0.01$ \\
\hline Rehabilitation professionals & $0.0(0.0-0.0)$ & $0.0(0.0-0.0)$ & $0.0(0.0-0.0)$ & $0.0(0.0-0.0)$ & 0.29 \\
\hline $\begin{array}{l}\text { Patients with dementia } \\
\text { receiving antipsychotics (\%) }\end{array}$ & $30.0(20.0-50.0)$ & $30.0(20.0-50.0)$ & $35.0(20.0-50.0)$ & $30.0(20.0-50.0)$ & 0.13 \\
\hline
\end{tabular}

Missing values: setting $(n=37,6.4 \%)$, opening days/week $(n=43 ; 7.4 \%$, opening hours/week $(n=43,7.4 \%)$, waiting time for the first visit $(n=70,12.1 \%)$, overall patients $(n=93,16.1 \%)$, referrals/month $(n=66,11.4 \%)$ neuropsychological assessment $(n=92,15.9 \%)$, caregiver support activities $(n=118,20.4 \%)$, electronic database $(n=70,12.1 \%)$, integrated care pathway $(n=79,13.7 \%)$, diagnostic categories $(n=87$, $15.1 \%)$, staff composition $(n=123,21.3 \%)$.

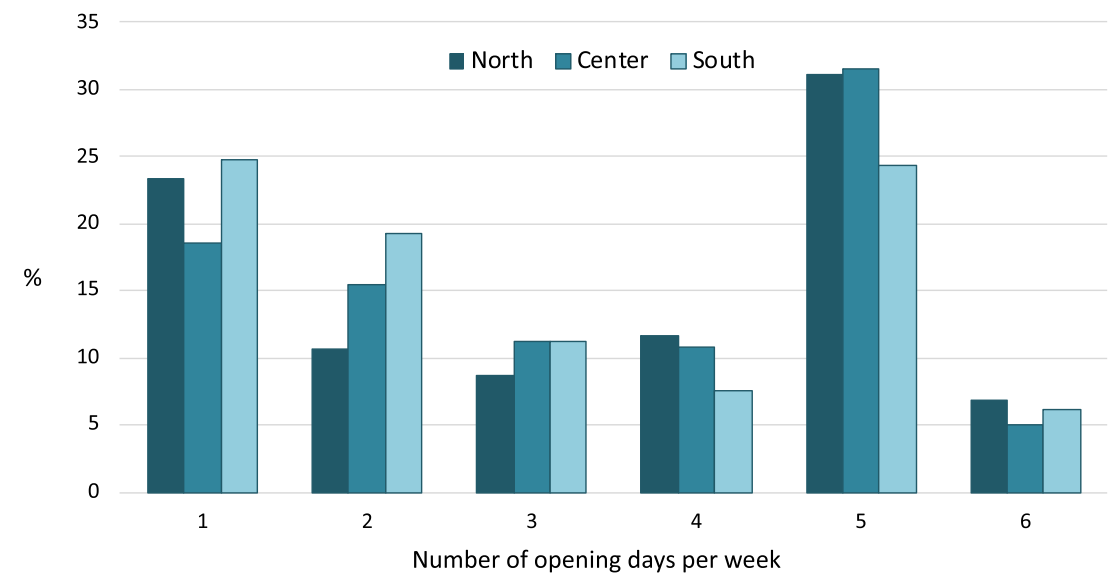

Fig. 2. Opening days per week of Italian CCDDs by geographic macro-area. Data are expressed as \%. 
Table 2

Diagnostic procedures performed among Italian CCDDs at the national level and by geographic macro-area. Data are expressed as \%

\begin{tabular}{|c|c|c|c|c|c|}
\hline & $\begin{array}{c}\text { Overall } \\
(n=577)\end{array}$ & $\begin{array}{c}\text { North } \\
(n=260)\end{array}$ & $\begin{array}{c}\text { Center } \\
(n=103)\end{array}$ & $\begin{array}{c}\text { South } \\
(n=214)\end{array}$ & $p$ \\
\hline Clinical assessment & 91.2 & 90.8 & 93.2 & 90.7 & 0.72 \\
\hline Neuropsychological assessment & 88.4 & 88.8 & 92.2 & 86.0 & 0.25 \\
\hline Routine blood tests & 71.1 & 74.2 & 67.0 & 69.2 & 0.29 \\
\hline Electroencephalography & 43.3 & 49.6 & 38.8 & 37.9 & 0.02 \\
\hline Brain CT & 69.7 & 73.1 & 66.0 & 65.9 & 0.18 \\
\hline Brain MRI & 65.5 & 68.5 & 65.0 & 62.1 & 0.35 \\
\hline Brain volumetric MRI & 16.8 & 16.5 & 21.4 & 15.0 & 0.35 \\
\hline Brain functional MRI & 22.7 & 23.5 & 24.3 & 21.0 & 0.75 \\
\hline Brain perfusion SPECT $/{ }^{18}$ FDG PET & 50.3 & 58.5 & 42.7 & 43.9 & 0.001 \\
\hline CSF AD biomarkers & 30.2 & 42.3 & 27.2 & 16.8 & $<0.001$ \\
\hline Genetic testing AD/FTD mutations & 26.9 & 33.1 & 25.2 & 20.1 & 0.006 \\
\hline
\end{tabular}

$\mathrm{AD}$, Alzheimer's disease; CSF, cerebrospinal fluid; CT, computed tomography; FTD, frontotemporal dementia; MRI, magnetic resonance imaging; PET, positron emission tomography; SPECT, single photon emission computed tomography.

universities, had a lower number of overall patients and monthly referrals, shorter waiting times for the first visit, and a lower presence of psychologists relative to the other two geographic macro-areas. Moreover, they less commonly had an electronic database available, were less frequently part of an integrated care pathway, and had lower access to CSF biomarkers and genetic testing AD/FTD mutations A higher proportion of CCDDs from the northern regions reported having a geriatrician as part of their staff whereas the services from Central Italy were mostly leaded by neurologists. Conversely, psychiatrists were poorly represented in all Italian regions.

\section{Predictors of selected structure and outcome indicators}

The factors that resulted to be significantly, positively associated with a high number of monthly referrals were the hospital (PRR: 1.19, 95\%CI: 1.01$1.40 ; p=0.04$ ) or university (PRR: $1.45,95 \% \mathrm{CI}$ : $1.15-1.83 ; p<0.01)$ affiliation compared to territorial setting, the higher number of weekly opening hours (PRR: 1.77, 95\%CI: $1.37-2.29 ; p<0.001$ ) and overall patients attending the service (PRR: $2.60,95 \% \mathrm{CI}$ : $1.92-3.50 ; p<0.001)$, the provision of support activities for caregivers (PRR: 1.23, 95\%CI: 1.04-1.44; $p=0.01$ ), and the presence of geriatricians (PRR: 1.19, 95\%CI: $1.01-1.39 ; p=0.04)$ and/or rehabilitation professionals (PRR:1.17, 95\%CI: $1.00-1.38$ ) in the staff (Table 3 ).

The proportion of patients with a dementia diagnosis receiving antipsychotics was negatively associated with the availability of geriatricians (PRR: $0.81,95 \%$ CI: $0.66-1.00 ; p=0.05$ ) and/or psychologists in the CCDD (PRR: 0.78, 95\%CI: 0.63-0.96;
Table 3

Multivariate Poisson regression model of factors predicting a number of monthly referrals higher than the median value

\begin{tabular}{lccc}
\hline & PRR $^{*}$ & 95\%CI & $p$ \\
\hline Setting & & & \\
Territorial & 1.00 & - & - \\
Hospital & 1.19 & $1.01-1.40$ & 0.04 \\
University & 1.45 & $1.15-1.83$ & $<0.01$ \\
Opening hours/week $^{* *}$ & 1.77 & $1.37-2.29$ & $<0.001$ \\
Overall patients $^{\quad \text { attending the CCDD }}{ }^{* *}$ & 2.60 & $1.92-3.50$ & $<0.001$ \\
Caregiver support activities $^{\circ}$ & 1.23 & $1.04-1.44$ & 0.01 \\
Geriatricians $^{\circ}$ & 1.19 & $1.01-1.39$ & 0.04 \\
Rehabilitation professionals $^{\circ}$ & 1.17 & $1.00-1.38$ & 0.05 \\
Geographic macro-area $^{\text {North }}$ & & & \\
Center & 1.00 & - & - \\
South & 0.99 & $0.81-1.20$ & 0.90 \\
\hline
\end{tabular}

*Prevalence risk ratios. ${ }^{* *}$ Opening hours/week and overall patients ( $>$ median versus $<=$ median). ${ }^{\circ}$ Caregiver support activities, geriatricians, and rehabilitation professionals (presence versus absence).

$p=0.02$ ) whereas it was directly associated with the high share of referred individuals with subjective cognitive decline (PRR: 1.27, 95\%CI: 1.04-1.55; $p=0.02)$ (Table 4).

The determinants that emerged to be positively associated with a longer waiting time for the first visit were the hospital affiliation (PRR: $1.70,95 \% \mathrm{CI}$ : $1.11-2.60 ; p=0.02)$, a higher number of overall patients attending the service (PRR: $1.71,95 \% \mathrm{CI}$ : $1.13-2.58 ; p=0.01$ ) whereas the presence of psychiatrists in the staff (PRR: 0.44, 95\%CI: 0.20-0.98; $p=0.04$ ) was inversely associated with this indicator (Table 5).

None of the three indicators considered as dependent variables of interest in these models were significantly predicted by the geographic macroareas of CCDDs. 
Table 4

Multivariate Poisson regression model of factors predicting a proportion of patients receiving antipsychotics higher than the median value

\begin{tabular}{|c|c|c|c|}
\hline & PRR* $^{*}$ & $95 \% \mathrm{CI}$ & $p$ \\
\hline \multicolumn{4}{|l|}{ Setting } \\
\hline Territorial & 1.00 & - & - \\
\hline Hospital & 1.11 & $0.89-1.38$ & 0.33 \\
\hline University & 0.87 & $0.57-1.32$ & 0.52 \\
\hline $\begin{array}{l}\text { Subjective } \\
\text { cognitive decline** }\end{array}$ & 1.27 & $1.04-1.55$ & 0.02 \\
\hline $\begin{array}{l}\text { Neuropsychological } \\
\text { assessment }{ }^{\circ}\end{array}$ & 1.21 & $0.99-1.47$ & 0.06 \\
\hline Geriatricians $^{\circ}$ & 0.81 & $0.66-1.00$ & 0.05 \\
\hline Psychologists ${ }^{\circ}$ & 0.78 & $0.63-0.96$ & 0.02 \\
\hline \multicolumn{4}{|l|}{ Geographic macro-area } \\
\hline North & 1.00 & - & - \\
\hline Center & 1.06 & $0.81-1.39$ & 0.65 \\
\hline South & 1.06 & $0.84-1.34$ & 0.62 \\
\hline
\end{tabular}

* prevalence risk ratios. ${ }^{* *}$ Subjective cognitive decline (> median versus $<=$ median). ${ }^{\circ}$ Neuropsychological assessment, geriatricians, and psychologists (presence versus absence).

Table 5

Multivariate Poisson regression model of factors predicting a waiting time for the first visit longer than the median value

\begin{tabular}{lccc}
\hline & PRR $^{*}$ & $95 \%$ CI & $p$ \\
\hline Setting & & & \\
Territorial & 1.00 & - & - \\
Hospital & 1.70 & $1.11-2.60$ & 0.02 \\
University & 1.49 & $0.76-2.94$ & 0.25 \\
Overall patients & 1.71 & $1.13-2.58$ & 0.01 \\
$\quad$ attending the CCDD** & & & \\
Subjective cognitive decline** & 0.71 & $0.49-1.03$ & 0.07 \\
Psychiatrists & \\
Geographic macro-area & 0.44 & $0.20-0.98$ & 0.04 \\
North & & & \\
Center & 1.00 & - & - \\
South & 0.85 & $0.53-1.34$ & 0.35 \\
& 0.72 & $0.44-1.15$ & 0.17 \\
\hline
\end{tabular}

*Prevalence risk ratios. ${ }^{* *}$ Overall patients and subjective cognitive decline ( $>$ median versus $<=$ median). ${ }^{\circ}$ Psychiatrists (presence versus absence).

\section{DISCUSSION}

The present study aimed to systematically survey the characteristics of Italian CCDDs, to document existing discrepancies in the structure and activity of these services, and to identify those attributes that may be associated with higher standards of care in these settings.

Based on this survey, Italian CCDDs appear to be present throughout the national territory. With some exception, their geographic location mostly reflects the number of residents living in the different regions (i.e., most of services were mapped in Campania, Lombardia, Emilia Romagna, Veneto, and Sicilia that are among the most populated Italian regions). On the other hand, their distribution seems less consistent with the epidemiological dimensions of the dementia phenomenon at the local level. Indeed, the estimated catchment populations of CCDDs vary widely across the country. For instance, in Calabria there are 36 CCDDs to assess the approximately 32,000 patients with dementia estimated in that region. In Lazio, a similar number of services (i.e., 34) must instead serve about 98,000 potential people with dementia in the region. These findings should inform legislators and policymakers about the need of realigning the healthcare system to the epidemiological scenario of dementia. This approach would allow a better allocation of the (few) available health- and social-care resources.

A marked heterogeneity among the surveyed CCDDs was observed in relation to administrative characteristics, structure, affiliation, staff composition, services provided, and accessibility to diagnostic procedures. This variability in the organization and provision care of memory clinics had already emerged in previous surveys conducted in other World countries [11-15, 25] and was partially attributed to the lack of national and international agreement on the composition, activities, and standards of these services [12]. Accounting for the local peculiarities and discrepancies of dementia resources is crucial for the development of national strategies and guidance. Indeed, it is necessary (albeit extremely challenging) to design a model of care that takes into account that some CCDDs are open every day of the week while others are only open for a few hours. It must be considered that in some CCDDs a comprehensive clinical evaluation is provided while in others the clinical standards are definitely lower. Accordingly, the possibility of the services to make a more refined (and biomarker-based) diagnosis of the various dementia etiologies is very variable across the country. Nowadays, the availability of data on the access to CSF and neuroimaging assessments in "real world" clinical services would assume a special relevance as the possible approval of disease-modifying therapies for $\mathrm{AD}$ [26] will lead to a probable transformation in the functioning and organization of CCDDs [27]. Indeed, the accurate differentiation of $\mathrm{AD}$ from other pathological conditions and the evaluation of patients' eligibility to treatment will require early biomarkers testing. Moreover, the administration of these therapies will be accompanied by the need for closer clinical follow-up and repeated brain imaging to ascertain their safety/tolerability profiles. 
In Italy, the likely existence of a north-south gradient toward a lower availability of resources should also be acknowledged. These geographic inequalities were already observed in a previous analysis of the data collected by this survey that documented how CCDDs in Southern Italy less frequently provide a comprehensive neuropsychological assessment (based on a minimum core of tests measuring the main cognitive functions) relative to services in Northern and Central regions [28].

In this complex portrait, the identification of the characteristics of CCDDs that are associated with better outcomes would constitute an added value. In the study, we conducted exploratory analyses aiming to detect the predictors of positive outcomes in the CCDD setting. These analyses, that should be exclusively regarded as hypotheses-generating rather than conclusive, suggest how the higher-resourced services can provide better care and support to patients with dementia. Indeed, those centers that are open several days a week, are equipped with multidisciplinary staff (e.g., rehabilitation professionals, psychologists), or provide a multidimensional clinical assessment (due to the presence of a geriatrician) meet several structure and outcome indicators (i.e., high number of monthly referrals, short waiting times, low use of antipsychotics) that are suggestive for higher standards of care.

Some limitations of the present study are worth to be mentioned and discussed. First, the survey was based on data from self-administered questionnaires. Thus, it was not possible to ensure the correctness and validity of the answers received that may have been influenced by the perceptions of respondents. For example, $85 \%$ of CCDDs from Southern Italy reported to offer a neuropsychological assessment. Nevertheless, we had already shown that only about $30 \%$ of these services actually provide a comprehensive cognitive evaluation meeting sufficient quality standards (28). Second, even if updating and monitoring activities were carried out during the entire duration of the survey, it is not possible to guarantee that all the data presented in this report are up to date. In this regard, the survey will be updated in the coming years as part of the recently promulgated National Fund for Dementia of the Ministry of Health. Moreover, some important aspects of dementia care (e.g., prevalence of dementia subtypes, non-pharmacological approaches other than psychosocial interventions, relationships with general practitioners and patient associations, patients' follow-up, cross-cultural cognitive assessment) [29] were not covered by the questionnaire. Finally, a relevant frequency of missing data was present for several variables (Table 1).

This study has also several strengths. In particular, the survey achieved a very high response rate (i.e., 96.6\%) and saw the participation of almost all national CCDDs. This result is far superior to what has been achieved by other memory clinics surveys conducted in other countries. Such excellent participation is the result of a widespread interaction with regional delegates, healthcare districts, individual healthcare professionals. In addition to guaranteeing the success of the survey, this collaborative approach with local services and communities is fundamental for creating a national identity and collaboration about dementia. Moreover, the validation of the survey questionnaire in a pilot survey, the identification of indicators to document and monitor the quality of care, as well as the developed webbased data entry system capable to collect, update, and display the validated and/or officially confirmed list of available services as a dynamic online map easily accessible from the Dementia Observatory website (https://demenze.iss.it/), enhance the quality and implications of the findings.

In conclusion, we have provided a snapshot of the organization and activities of CCDDs in Italy and documented existing inequalities in the provision of care. These data are crucial for fostering the harmonization of the clinical approach to dementia, the planning of healthcare provision, and the allocation of available resources.

\section{ACKNOWLEDGMENTS}

We thank the designed delegates from each Italian region and autonomous province and all CCDD representatives. The study was funded by the Italian Ministry of Health (Project CCM 2013).

Authors' disclosures available online (https:// www.j-alz.com/manuscript-disclosures/21-0634r2).

\section{SUPPLEMENTARY MATERIAL}

The supplementary material is available in the electronic version of this article: https://dx.doi.org/ 10.3233/JAD-210634.

\section{REFERENCES}

[1] WHO | Global action plan on the public health response to dementia 2017-2025 [Internet]. WHO. World Health 
Organization; [cited 2021 Mar 24]. Available from: http://www.who.int/mental_health/neurology/dementia/ action_plan_2017_2025/en/

[2] GBD 2016 Dementia Collaborators (2019) Global, regional, and national burden of Alzheimer's disease and other dementias, 1990-2016: A systematic analysis for the Global Burden of Disease Study 2016. Lancet Neurol 18, 88-106.

[3] Wimo A, Guerchet M, Ali GC, Wu YT, Prina AM, Winblad B, Jönsson L, Liu Z, Prince M (2017) The worldwide costs of dementia 2015 and comparisons with 2010. Alzheimers Dement 13, 1-7.

[4] Van der Cammen TJ, Simpson JM, Fraser RM, Preker AS, Exton-Smith AN (1987) The Memory Clinic. A new approach to the detection of dementia. Br J Psychiatry $J$ Ment Sci 150, 359-364.

[5] Alzheimer's Disease International. World Alzheimer Report 2011. The benefits of early diagnosis and intervention. 2011.

[6] Banerjee S, Willis R, Matthews D, Contell F, Chan J, Murray $\mathrm{J}$ (2007) Improving the quality of care for mild to moderate dementia: An evaluation of the Croydon Memory Service Model. Int J Geriatr Psychiatry 22, 782-788.

[7] Ramakers IHGB, Verhey FRJ (2011) Development of memory clinics in the Netherlands: 1998 to 2009. Aging Ment Health 15, 34-39.

[8] Logiudice D, Waltrowicz W, Brown K, Burrows C, Ames D, Flicker L (1999) Do memory clinics improve the quality of life of carers? A randomized pilot trial. Int J Geriatr Psychiatry 14, 626-632.

[9] Rubinsztein JS, van Rensburg MJ, Al-Salihy Z, Girling D, Lafortune L, Radhakrishnan M, Brayne C (2015) A memory clinic v. traditional community mental health team service: Comparison of costs and quality. BJPsych Bull 39, 6-11.

[10] Banerjee S, Wittenberg R (2009) Clinical and cost effectiveness of services for early diagnosis and intervention in dementia. Int J Geriatr Psychiatry 24, 748-754.

[11] Mehrani I, Kochan NA, Ong MY, Crawford JD, Naismith SL, Sachdev PS (2021) Organisational aspects and assessment practices of Australian memory clinics: An Australian Dementia Network (ADNeT) Survey. BMJ Open 11, e038624.

[12] Cahill S, Pierce M, Moore V (2014) A national survey of memory clinics in the Republic of Ireland. Int Psychogeriatr 26, 605-613.

[13] Foy J (2008) A survey of memory clinic practice in Scotland. Psychiatr Bull 32, 467-469.

[14] Cheung G, Strachan J (2008) A survey of memory clinics in New Zealand. Australas Psychiatry Bull R Aust N Z Coll Psychiatr 16, 244-247.

[15] Le Duff F, Develay AE, Quetel J, Lafay P, Schück S, Pradier C, Robert P; French National Alzheimer dataBank (BNA) (2012) The 2008-2012 French Alzheimer Plan: Description of the National Alzheimer Information System. J Alzheimers Dis 29, 891-902.

[16] Di Fiandra T, Canevelli M, Di Pucchio A, Vanacore N, Italian Dementia National Plan Working Group (2015) The Italian Dementia National Plan. Commentary. Ann Ist Super Sanita 51, 261-264.

[17] Wimo A, Jönsson L, Gustavsson A, McDaid D, Ersek K, Georges J, Gulácsi L, Karpati K, Kenigsberg P, Valtonen $\mathrm{H}$ (2011) The economic impact of dementia in Europe in 2008-cost estimates from the Eurocode project. Int J Geriatr Psychiatry 26, 825-832.

[18] Presidenza del Consiglio dei Ministri Conferenza, Unificata. Provvedimento 30 ottobre 2014. Accordo, ai sensi dell' articolo 9, comma 2, lett. c) del decreto legislativo 28 agosto 1997, n. 281, tra il Governo, le regioni e le province autonome di Trento e di Bolzano, le province, i comuni e le comunitá montane sul documento recante: «Piano nazionale demenze. Strategie per la promozione ed il miglioramento della qualitá e dell'appropriatezza degli interventi assistenziali nel settore delle demenze». (Rep. atti n. 135/CU). Gazzetta Ufficiale n. 9, 13 gennaio 2015.

[19] Sorrentino GC, Caffari B, Vanacore N, Maggini M, Raschetti R (2005) The characteristics of Alzheimer's Disease Units in relation to neuropsychological tests. Ann Ist Super Sanita 41, 63-68.

[20] Bianchi G, Gasparini M, Caffari B, Sorrentino GC, Bianchi C, Bruno G, Maggini M, Raschetti R, Vanacore N (2005) Use of neuropsychological tests in the Cronos Project. Ann Ist Super Sanita 41, 69-74.

[21] Di Pucchio A, Di Fiandra T, Marzolini F, Lacorte E, SQoDS Group, Vanacore N (2017) Survey of health and socialhealth services for people with dementia: Methodology of the Italian national project. Ann Ist Super Sanita 53, 246252.

[22] Agenzia Italiana del Farmaco (AIFA). Nota AIFA 85 Determinazione AIFA 22 settembre 2009. Gazzetta Ufficiale $n$. 238 del 13 ottobre 2009;

[23] Kelley K, Clark B, Brown V, Sitzia J (2003) Good practice in the conduct and reporting of survey research. Int J Qual Health Care J Int Soc Qual Health Care 15, 261-266.

[24] Bacigalupo I, Mayer F, Lacorte E, Di Pucchio A, Marzolini F, Canevelli M, Di Fiandra T, Vanacore N (2018) Systematic review and meta-analysis on the prevalence of dementia in Europe: estimates from the highest-quality studies adopting the DSM IV diagnostic criteria. J Alzheimers Dis 66, 14711481.

[25] Woodward MC, Woodward E (2009) A national survey of memory clinics in Australia. Int Psychogeriatr 21, 696-702.

[26] Fillit H, Green A (2021) Aducanumab and the FDA where are we now? Nat Rev Neurol 17, 129-130.

[27] Hlavka JP, Mattke S, Liu JL (2019) Assessing the Preparedness of the Health Care System Infrastructure in Six European Countries for an Alzheimer's Treatment. Rand Health $Q$ [Internet]. 2019 May 16 [cited 2021 Mar 25]; 8(3). Available from: https://www.ncbi.nlm.nih. gov/pmc/articles/PMC6557037/.

[28] Di Pucchio A, Vanacore N, Marzolini F, Lacorte E, Di Fiandra T; I-DemObs Group, Gasparini M (2018) Use of neuropsychological tests for the diagnosis of dementia: A survey of Italian memory clinics. BMJ Open 28, 8:e017847.

[29] Canevelli M, Lacorte E, Cova I, Cascini S, Bargagli AM, Angelici L, Giusti A, Pomati S, Pantoni L, Vanacore N; ImmiDem Study Group (2020) Dementia among migrants and ethnic minorities in Italy: Rationale and study protocol of the ImmiDem project. BMJ Open 10, e32765. 